\title{
PELAKSANAAN KETENTUAN PREMI DANA PIHAK KETIGA OLEH LEMBAGA PENJAMIN SIMPANAN PADA BANK PERKREDITAN RAKYAT
}

\author{
Oleh \\ Gede Ryan Febrasio Wikora* \\ Ida Ayu Sukihana**
Program Kekhususan Hukum Bisnis Fakultas Hukum Universitas Udayana

\begin{abstract}
ABSTRAK
Bank Perkreditan Rakyat (BPR) adalah lembaga keuangan bank yang menerima simpanan hanya dalam bentuk deposito berjangka, tabungan, dan/atau bentuk lainnya yang dipersamakan dengan itu dan menyalurkan dana sebagai usaha BPR. Lembaga Penjamin Simpanan (LPS) menjadi begitu dibutuhkan mengingat banyaknya bank-bank regional maupun bank nasional yang mengalami pailit. Tujuan penelitian ini untuk mengetahui peraturan premi dana pihak ketiga serta tingkat bunga yang dapat dijamin oleh LPS. Penelitian yang digunakan adalah yuridis empiris atau tatsachenwissenschaft merupakan suatu ilmu kenyataan hukum yang terdiri dari penelitian terhadap efektivitas hukum serta penegakan hukum dalam masyarakat dengan jenis pendekatan yang dilakukan dalam penelitian ini adalah jenis pendekatam Perundang-undangan (The Statue Approach). Teknik pengumpulan data yang dipergunakan dalam penulisan hukum ini adalah dengan studi dokumen atau metode penelitian kepustakaan(Library research) yang diperoleh dengan membaca serta mengutip buku-buku maupun peraturan perundang-undangan yang berhubungan dengan permasalahan dan pendekatan fakta ( The Fact Approach) pendekatan yang berdasarkan fakta-fakta yang terjadi di lapangan atau di masyarakat yang sesuai dengan permasalahan yang diteliti.
\end{abstract}

yang disajikan dan menggunakan teknik wawancara. Hasil penelitian menunjukkan bahwa Penerapan Pasal 38 ayat 1 Peraturan Lembaga Penjamin Simpanan Nomor 1/PLPS/2006

${ }^{*}$ Gede Ryan Febrasio Wikora (1316051176) adalah Mahasiswa Bagian Hukum Bisnis Fakultas Hukum Universitas Udayana, Selaku penulis pertama, alamat : Jl tukad Barito 1 Nomor.10, Korespondensi dengan penulis melalui email: ryanfwikoragede@gmail.com

** Ida Ayu Sukihana,SH.,MH. (NIP: 195703111986012001) adalah Dosen Bagian Hukum Bisnis Fakultas Hukum Universitas Udayana, Alamat Jl Trengguli GG XXII Br. Ling Tembau Tengah Denpasar. 
tentang Program Penjaminan Simpanan di BPR Mulia Wacana dilakukan sesuai dengan aturan dan tidak menaikan suku bunga yang ditetapkan oleh Lembaga Penjamin Simpanan dan akibat hokum jika BPR menaikan tingkat suku bunga yang di tetapkan oleh LPS maka dana pihak ketiga yang di simpan di BPR tidak akan di jamin oleh LPS.

Kata Kunci : BPR , LPS , Suku Bunga 


\begin{abstract}
Rural Bank (BPR) is a bank financial institution that accepts deposits only in the form of time deposits, savings deposits, and / or other equivalent forms and disbursed funds as BPR business. The Deposit Insurance Corporation (LPS) is becoming so necessary given the large number of regional banks and national banks that are experiencing bankruptcy. The purpose of this study is to determine the arrangements for third party fund premiums and interest rates that can be guaranteed. The research used is empirical juridical or tatsachenwissenschaft is a science of legal reality which consists of research on the effectiveness of law and law enforcement in society with the type of approach undertaken in this study is the type of legislation approach (The Statue Approach). Data collection techniques used in the writing of this law is to study documents or research methods library (Library research) obtained by reading and quoting books and legislation related to the problems and fact approach (The Fact Approach) approach based on facts that occur in the field or in the community in accordance with the problems studied. presented and using interview techniques. The results of the research indicate that the application of Article 38 paragraph 1 of the Regulation of Deposit Insurance Agency Number 1 / PLPS / 2006 concerning Deposit Guarantee Program in BPR Mulia Wacana is conducted in accordance with the rules and does not raise the interest rate stipulated by the Deposit Insurance Corporation and the legal consequences if the BPR raises the tribe rate interest that is set by LPS then third party funds deposited in the BPR will not be guaranteed by LPS.
\end{abstract}

\title{
Keywords: BPR, LPS, Interest Rate
}

\section{PENDAHULUAN}

\subsection{LATAR BELAKANG MASALAH}

Asuransi sangat diperlukan pada masa ini oleh individu yang memiliki nilai ekonomis, sehingga asuransi dapat dijadikan alat untuk menjaga nilai ekonomis seseorang. Kondisi yang tidak dapat diprediksi yang bersifat alami tersebut membuat adanya keadaan yang tidak dapat diprediksi lebih dahulu. Sehingga setiap masyarakat tidak dapat memprediksi lebih dulu dengan suatu tindakan yang pasti. Dengan tidak adanya suatu kepastian, tentu ada saat dimana keadaan yang tidak dapat diprediksi. Kondisi tidak pasti tersebut dapat berupa bentuk dan peristiwa, yang 
biasanya akan di hindari. Kondisi yang tidak dapat diprediksi terhadap setiap peluang yang dapat terjadi baik dalam bentuk atau kejadian yang belum tentu, memicu rasa tidak aman atau bisa disebut sebagai ancaman dalam kehidupan sehari-hari. ${ }^{1}$ Dalam hidup seseorang, tanpa dipahami banyak sekali resiko dan bahaya yang mengelilingi kehidupan individu, setiap individu pasti akan mengalami risiko baik berat maupun ringan. Untuk meminimalisir risiko yang terjadi dikemudian hari seperti risiko kerugian, risiko akibat bencana alam, risiko macetnya pembayaran kredit bank ataupun risiko yang lain yang dapat merugikan seseorang, maka diperlukannya asuransi untuk meminimalisir risiko-risiko yang tidak dapat di prediksi, dan masyarakat dapat menanggulangi risiko tersebut pada perusahaan asuransi. Perusahaan asuransi yang dapat menganggung risiko yang akan dihadapi nasabahnya baik perorangan maupun badan usaha. Hal ini dikarenakan perusahaan asuransi merupakan perusahaan yang melakukan usaha pertanggung jawaban terhadap risiko yang akan dihadapi oleh nasabahnya. Aturan hukum positif dari asuransi ini di atur dalam Undang-undang nomor 2 tahun 1992 tentang Usaha Perasuransian. Sebagai halnya diketahui bahwa Negara Indonesia mengenal dunia perbankan dari negara yang pernah menjajah Indonesia yaitu Belanda. maka dari itu, sejarah perbankan sangat dipengaruhi oleh negara yang sempat menjajah Indonesia. Pengaruh Negara belanda juga mempengaruhi baik bank pemerintah dan bank swasta nasional. ${ }^{2}$ Bank adalah kolaborator untuk melengkapi kepentingan keuangan masyarakat di kehidupan sehari-hari. Bank juga menjadi tempat untuk melaksanakan beragam transaksi yang ada hubungannya dengan keuangan seperti tempat yang paling aman untuk menyimpan uang, melakukan transfer uang atau membayar tagihan setiap bulan. ${ }^{3}$ Bank yang menjalankan kegiatan usahanya secara konvensional menggunakan istilah kredit, sedangkan bank yang menjalankan

${ }^{1}$ Sri Rejeki Hartono, 2008, Hukum Asuransi dan Perusahaan Asuransi, Jakarta; Sinar Grafika, hal.2

${ }_{2}^{2}$ Zainal Asikin, 2015, Pengantar Hukum Perbankan Indonesia, Jakarta; PT Raja Grafindo Persada, hal.7

${ }^{3}$ Kasmir, 2008, Pemasaran Bank, edisi revisi cet. Ke-3, Jakarta;Kencana, hal.7 
usahanya berdasarkan syariah menggunakan istilah pembiayaan berdasarkan prinsip syariah. ${ }^{4}$

Bank Perkreditan Rakyat yang selanjutnya disebut BPR, BPR adalah salah satu lembaga keuangan yang memiliki fungsi untuk menerima uang dari masyarakat untuk ditabung dan mengalirkan kembali uang yang ditabung oleh masyarakat kepada masyarakat itu sendiri untuk kebutuhan mereka sendiri atau financial intermediary. ${ }^{5}$ Akhirnya, kedudukan LPS menjadi sangat penting mengingat terlalu banyak bank-bank regional maupun bank nasional yang mengalami gulung tikar atau pailit. Aturan mengenai Lembaga Penjamin Simpanan ini diatur dalam UndangUndang Nomor 24 tahun 2004 Tentang Lembaga Penjamin Simpanan yang berlaku efektif pada bulan September 2005. Dalam Undang-Undang perasuransian aturan mengenai premi terdapat pada Pasal 1 huruf a ketentuan umum Undang-Undang Nomor 40 tahun 2014 tentang perasuransian yang menyatakan "memberikan penggantian kepada tertanggung atau pemegang polis karena kerugian, kerusakan, biaya yang timbul, kehilangan keuntungan, atau tanggung jawab hukum kepada pihak ketiga yang mungkin diderita tertanggung atau pemegang polis karena terjadinya suatu peristiwa yang tidak pasti", aturan mengenai pembayaran premi LPS, diatur dalam PLPS Nomor 1/LPS/2007 tentang Program Penjaminan Simpanan Pasal 38 ayat (1) yang menyatakan "Nasabah penyimpan dinyatakan sebagai pihak yang diuntungkan secara tidak wajar sebagaimana dimaksud dalam Pasal 36 huruf b, antara lain apabila nasabah tersebut memperoleh tingkat bunga melebihi maksimum tingkat bunga penjaminan yang ditetapkan LPS"

\subsection{Rumusan Masalah}

1. Bagaimana pelaksanaan pengaturan mengenai premi dana pihak ketiga oleh Lembaga Penjamin Simpanan pada Bank

${ }^{4}$ Putra, I Wayan Erik Pratama; Ni Ketut Supasti Dharmawan; Ni Putu Purwati. 2016. Implementasi Perjanjian Kredit Yang Dibuat Secara Di Bawah Tangan Pada Bpr Di Kecamatan Kuta Utara Kabupaten Badung. Kertha Semaya. Hal.2

${ }^{5}$ Sri Susilo, 2000, Bank Dan Lembaga Keuangan Lain, Jakarta; Salemba Empat, hal.6 
Perkreditan Rakyat di Bank Perkreditan Rakyat Mulia Wacana?

2. Bagaimanakah jika bunga simpanan melebihi tingkat bunga wajar yang ditetapkan oleh LPS ?

\subsection{Tujuan Penulisan}

1. Untuk mengetahui pengaturan premi pihak ketiga oleh LPS kepada bank perkreditan rakyat.

2. Untuk mengetahui pelaksanaan peraturan mengenai premi dana pihak ketiga yang dijamin oleh Lembaga Penjamin Simpanan.

3. Untuk mengetahui syarat yang harus diketahui nasabah jika ingin dananya di jamin oleh Lembaga Penjamin Simpanan.

\section{ISI MAKALAH}

\subsection{Metode Penelitian}

Jadi jenis penelitian yang gunakan untuk studi kasus ini adalah yuridis empiris atau tatsachenwissenschaft merupakan suatu ilmu kenyataan hukum yang terdiri dari penelitian terhadap efektivitas hukum serta penegakan hukum dalam masyarakat. Hukum sebagai suatu gejala emperis yang dapat diamati dalam kehidupan nyata berdasarkan fakta yang terjadi dilapangan dan implementasi ketentuan undang-undang. 6 Jadi penelitian efektivitas hukum adalah dimana penelitian yang di dalamnya terdapat bagaimana hukum beroperasi kepada masyarakat. penelitian yang membahas bagaimana hukum beroperasi.

\footnotetext{
${ }^{6}$ Amirudin, H Zinal Azikin, 2004, Pengantar Metode Penelitian, PT Raja Grafindo Persada, Jakarta. hal. 58
} 


\subsection{Hasil dan Analisis}

\subsubsection{Terjadinya Proses Program Penjamin Dana Pihak Ketiga di BPR}

Secara teori, kepesertaan didalam program penjaminan dapat bersifat wajib dan sukarela. Yang bersifat wajib diartikan agar dapat menghindari adanya kecenderungan bank yang memiliki risiko kegagalan yang tinggi. Berdasarkan wawancara dengan Wayan Swartika (direktur BPR Mulia Wacana) menjelaskan proses terjadinya program penjamin dana pihak ketiga oleh LPS di BPR adalah ketika nasabah dating ke BPR Mulia Wacana sebelum menyerahkan uang yang akan di taruh di BPR pihak BPR Mulia Wacana meminta fotocopy KTP dan nasabah harus mengisi formulir pembukaan rekening , setelah mengisi dengan lengkap pihak BPR menanyakan mengenai sumber dana yang akan di taruh di BPR jika sumber dana sudah jelas selanjutnya pihak BPR menjelaskan mengenai aturan suku bunga yang di tetapkan oleh LPS serta dana maksimal yang disimpan di BPR setelah nasabah menyetujui semua persyaratan dari BPR dan ketentuan-ketentuan dari LPS setelah itu nasabah menuju ke teller atau kasir untuk menyerahkan uang yang akan ditabung di BPR Mulia Wacana. Responden bernama I Wayan Mudra menjelaskan bahwa dirinya selaku nasabah merasa aman menabung di BPR Mulia Wacana karena sebelum menjadi nasabah sudah dijelaskan dari pihak bank terkait aturan-aturan mengenai uang yang akan disimpan di bank dan harus mengikuti aturan yang di tetapkan oleh Lembaga Penjamin Simpanan. 


\subsubsection{Pelaksanaan Pengaturan Premi Dana Pihak Ketiga Oleh Lembga Penjamin Simpanan di Bank Perkreditan Rakyat}

Penyaluran dari bank peserta dilakukan sebelum muncul bank yang dicabut izin usahanya melalui premi dan penerimaan lainnya yang diartikan sebagai cadangan penjaminan. ${ }^{7}$ Dengan pendanaan penyaluran yang akan dibayar oleh bank peserta juga tidak akan terlalu berfluktuasi. 8 Bentuk penyaluran dari pendanaan seperti diatas dari bank dalam penjaminan simpanan biasanya berupa premi. Premi mempunyai beberapa fungsi, yaitu untuk membiayai operasional penjaminan simpanan, diartikan dalam cadangan penjaminan, dan digunakan sebagai insentif untuk pengelolaan risiko yang lebih hatihati. Mengenai pelaksanaan perhitungan premi diatur dalam pasal 11 PLPS Nomor 1/PLPS/2007 tentang Program Penjaminan Simpanan yang mengatur:

1. Premi Penjaminan dibayarkan 2 kali dalam satu tahun.

2. Premi setiap periode sebagaimana di maksud pada ayat (1) ditetapkan sebesar $0,1 \%$ dari rata-rata 1 saldo bulan total simpanan dalam satu periode.

3. Total simpanan sebagaimana dimaksud pada ayat (2) mencakup pula simpanan berasal dari bank lain.

Pasal 13 PLPS Nomor 1/PLPS/2007 tentang Program Penjamin Simpanan yang berbunyi

\footnotetext{
${ }^{7}$ Rujito dkk, 2011, 5 tahun LPS Menjamin Simpanan Nasabah Dan Menjaga Stabilitas Sistem Perbankan, Jakarta; Lembaga Penjamin Simpanan, hal.14

${ }^{8}$ Ibid
} 
"Pembayaran premi pada awal periode sebagaimana dimaksud dalam Pasal 12 huruf a harus dilakukan paling lambat tanggal;

a. $\quad 31$ Januari, untuk periode 1 Januari sampai dengan30 Juni; dan

b. $\quad 31$ Juli, untuk periode 1 Juli sampai dengan 31 Desember."

Jadi premi, kontribusi kepesertaan,modal awal LPS, serta kekayaan yang berbentuk investasi yang ditempatkan pada surat beharga yang di terbitkan oleh pemerintah atau Bank Indonesia yang akan digunakan untuk membayar klaim penjamin dana nasabah apabila suatu bank mengalami sebuah kepailitan. Pembayaran tersebut akan dilakukan oleh LPS setelah melakukan rekonsiliasi beserta verifikasi simpanan yang dijamin terlebih dahulu untuk mengetahui apa klaim penjamin tersebut layak untuk dibayar atau tidak. ${ }^{9}$ Pelaksanaan di BPR Mulia Wacana Gianyar,yang beralamat di jl Raya Sukawati No.1 Kabupaten Gianyar, melakukan pembayaran premi pembayaran premi dari seluruh simpanan nasabah yang sesuai tingkat bunga yang ditetapkan oleh LPS dilakukan setahun 2 kali setiap 6 bulan untuk pembayaran premi dari bulan juli sampai desember dibayarkan pada bulan januari, pembayaran premi pada bulan januari sampai juni dibayarkan bulan juli. Dana nasabah yang dibayarkan preminya yaitu dana yang tidak melebihi 2 milyar. Selain itu BPR Udary yang beralamat di J1. Prof Ida Bagus Mantra No. 77 Kecamatan Sukawati-Gianyar juga melakukan hal yang sama yaitu

${ }^{9}$ Saputra, Sah Tobing, 2013, Naskah Publikasi Tinajuan Yuridis Mengenai Peranan Lembaga Penajmin Simpanan Dalam Perlindungannya Terhadap Dana Simpanan Nasabah Bank, Fakultas Hukum Universitas Muhammadiyah, hal.23 
membayar premi setahun 2 kali per 6 bulan sekali, untuk menjamin dana nasabah yang ada di BPR tersebut.

Dengan demikian peserta-peserta LPS terutama BPR , sudah menjalankan kewajibannya membayar premi kepada LPS sesuai dengan ketentuan Pasal 11 dan Pasal 13 PLPS Nomor 1/PLPS/2007 tentang Program Penjaminan Simpanan yang ditetapkan oleh LPS. Yang dilakulan per 6 bulan dalam setahun agar dana nasabah yang ada di BPR tersebut dapat dijamin oleh LPS.

\subsubsection{Pengaturan Tingkat Bunga Maksimal yang diatur dalam Lembaga Penjamin Simpanan}

Arti dari Tingkat suku bunga adalah dimana harga dari penggunaan uang yang dikatakan sebagai sewa atas penggunaan uang untuk jangka waktu tertentu. ${ }^{10}$ Begitu juga dengan suku bunga simpanan yang berarti bunga yang diberikan atas balas jasa bagi nasabah yang menyimpan uangnya di bank 11 Berdasarkan ketentuan Pasal 19 huruf b Undang-Undang Nomor 24 Thaun 2004 Tentang Lembaga Penjamin Simpanan, klaim penjaminan nasabah penyimpan dinyatakan tidak layak bayar apabila nasabah tersebut merupakan pihak yang diuntungkan secara tidak wajar. Nasabah penyimpan dinyatakan sebagai pihak yang diuntungkan secara tidak wajar apabila nasabah tersebut memperoleh tingkat bunga melebihi maksimum tingkat bunga penjaminan yang ditetapkan LPS. Simpanan yang dapat dijamin oleh Lembaga Penjamin Simpanan menurut Pasal 10 Undangundang No 24 Tahun 2004 yang berbunyi "Simpanan yang dijamin meliputi giro, deposito, sertifikat deposito, tabungan, dan

\footnotetext{
${ }^{10}$ Gusmao, Lourenco H.A.M, 2011, Analisis Pengaruh Tingkat Suku Bunga dan Tingkat Inflasi Terhadap Minat Menabung Konsumen Institute Of Business, Dili Timor Leste, hal.1

${ }^{11}$ Kasmir, 2014, Bank Dan Lembaga Keuangan Lainnya, Banjarmasin; Rajagrafindo Persada, hal.114
} 
atau bentuk lain yang dipersamakan dengan itu ". Sesuai dengan siaran pers Nomor : PRESS-2/SEKL/2017 tentang penetapan tingkat bunga penjaminan Periode Januari 2017 Lembaga Penjamin Simpanan telah melakukan evaluasi tingkat bunga penjaminan untuk simpanan dalam rupiah dan valuta asing di Bank Umum serta untuk simpanan dalam rupiah di Bank Perkreditan Rakyat, dimana Tingkat Bunga Penjaminan untuk periode 12 Januari 2017 sampai dengan Mei 2017 tidak mengalami perubahan dengan rincian sebagai berikut :

1. Tingkat bunga untuk BPR yaitu $8,75 \%$

2. Tingkat bunga untuk Bank Umum yaitu 6,25\%

3. Tingat Bunga untuk Valas 0,75\%

Menurut Wayan Swartika (Direktur BPR Mulia Wacana) menjelaskan mengenai tingkat bunga yang diatur oleh LPS selalu berubah-ubah dan BPR Mulia Wacana sudah memberi informasi mengenai tingkat suku bunga yang di tetapkan LPS kepada nasabah yang akan menaruh uangnya di BPR Mulia Wacana, mengenai perubahan tingkat suku bunga yang ditetapkan LPS, LPS akan memberi informasi kepada peserta-peserta LPS melalui email atau surat edaran. Dan setelah ada pembaharuan mengenai tingkat suku bunga tersebut pihak BPR Mulia Wacana akan segera mengubah informasi tingkat suku bunga sesuai dengan tingkat suku bunga yang di tetapkan oleh LPS. Bapak I wayan Swartika selaku (Direktur BPR Mulia Wacana) menjelaskan bahwa tingkat bunga yang dapat dijamin oleh Lembaga Penjamin Simpanan untuk saat ini bulan September 2017 sampai Januari 2018 tingkat bunga maksimal yang ditetapkan Lembaga Penjamin Simpanan adalah $8,75 \%$. Sanksi yang diberikan kepada BPR yang menaikkan suku tingkat bunga kepada nasabah, jika BPR tersebut menaikkan tingkat bunga diatas tingkat wajar yang 
ditetapkan Lembaga Penjamin Simpanan maka dana itu tidak akan di jamin oleh LPS. Selain itu bapak I Made Suarja juga menjelaskan bahwa di BPR Udary, sebelum nasabah itu menaruh uangnya, pihak BPR Udary telah menjelaskan mengenai suku tingkat bunga yang ditetapkan oleh LPS kepada pihak nasabah terlebih dahulu, sehingga tidak ada nasabah yang menerima suku tingkat bunga diatas batas wajar yang di tetapkan oleh LPS, dan semua dana yang ada di BPR Udary, tingkat suku bunga yang diberikan sudah sesuai dengan ketentuan yang diberikan oleh LPS.

Dengan demikian BPR Mulia Wacana dan BPR Udary, selaku BPR yang menjadi peserta LPS sudah mengikuti ketentuan tingkat suku bunga yang ditetapkan oleh LPS, agar tidak melebihi tingkat suku bunga batas wajar yang ditetapkan oleh LPS. Klaim penjaminan nasabah penyimpan dinyatakan tidak layak bayar apabila nasabah tersebut merupakan pihak yang diuntungkan secara tidak wajar. Nasabah penyimpan dinyatakan sebagai pihak yang diuntungkan secara tidak wajar apabila nasabah tersebut memperoleh tingkat bunga melebihi maksimum tingkat bunga penjaminan yang ditetapkan LPS.

\section{PENUTUP}

\subsection{KESIMPULAN}

Dilihat dari hasil pemaparan dalam bab-bab diatas, maka dapat ditarik kesimpulan sebagai berikut:

1. Pelaksanaan pengaturan mengenai premi dana pihak ketiga oleh Lembaga Penjamin Simpanan pada Bank Perkreditan Rakyat di Bank Perkreditan Rakyat Mulia Wacana dan Bank Perkreditan Rakyat Udary berjalan 
sesuai dengan peraturan yang berlaku tentang Lembaga Penjamin Simpanan.

2. Dalam hal bunga simpanan melebihi tingkat bunga wajar yang ditetapkan oleh LPS, pihak LPS tidak akan memeberikan klaim kepada bank yang dana pihak ketiganya mendapat bunga melebihi tingkat bunga wajar yang ditetapkan LPS.

\subsection{SARAN}

1. BPR dan LPS sekiranya dapat menjalankan penjaminan dana pihak ketiga yang ada dibank secara baik, agar dapat meningkatkan percayaan nasabah kepada bank untuk menyimpan uang di bank, supaya perekonomian Negara tetap stabil.

2. Dari kesimpulan penelitian ini didapatkan bahwa BPR telah melaksanakan pemberian informasi mengenai hak dan kewajiban menjadi peserta LPS kepada nasabah dan sudah menjalankan sesuai dengan aturan yang ditetapkan oleh LPS, maka dari itu BPR hendaknya mempertahankan apa yang sudah dijalankan selama ini. 


\section{DAFTAR PUSTAKA}

\section{BUKU}

Amirudin, H Zinal Azikin, 2004, Pengantar Metode Penelitian, PT Raja Grafindo Persada,

Kasmir, 2008, Pemasaran Bank, edisi revisi cet. Ke-3, Jakarta;Kencana,

Kasmir, 2014, Bank Dan Lembaga Keuangan Lainnya, Banjarmasin; Rajagrafindo Persada,

Rujito dkk, 2011, 5 tahun LPS Menjamin Simpanan Nasabah Dan Menjaga Stabilitas Sistem Perbankan, Jakarta; Lembaga Penjamin Simpanan,

Sri Rejeki Hartono, 2008, Hukum Asuransi dan Perusahaan Asuransi, Jakarta; Sinar Grafika,

Sri Susilo, 2000, Bank Dan Lembaga Keuangan Lain,

Zainal Asikin, 2015, Pengantar Hukum Perbankan Indonesia, Jakarta; PT Raja Grafindo Persada,

\section{JURNAL}

Gusmao, Lourenco H.A.M, 2011, Analisis Pengaruh Tingkat Suku Bunga dan Tingkat Inflasi Terhadap Minat Menabung Konsumen Institute Of Business, Dili Timor Leste

Putra, I Wayan Erik Pratama; Ni Ketut Supasti Dharmawan; Ni Putu Purwati, 2016, Implementasi Perjanjian Kredit Yang Dibuat Secara Di Bawah Tangan Pada Bpr Di Kecamatan Kuta Utara Kabupaten Badung. Kertha Semaya.

Saputra, Sah Tobing, 2013, Naskah Publikasi Tinajuan Yuridis Mengenai Peranan Lembaga Penajmin Simpanan Dalam Perlindungannya Terhadap Dana Simpanan Nasabah Bank, Fakultas Hukum Universitas Muhammadiyah,

\section{Undang-undang}

Undang - Undang Nomor 2 Tahun 1992 tentang Usaha Asuransi, Lemabran Negara Republik Indonesia Tahun 1992 Nomor 13, Tambahan Lembaran Negara Republik Indonesia Nomor 3467 
Undang-undang Nomor 24 tahun 2004 tentang Lembaga Penjamin Simpanan, Lembaran Negara Republik Indonesia Tahun 2004 Nomor 96.

Undang-undang Nomor 40 tahun 2014 tentang Perasuransian, Lemabran Negara Republik Indonesia Nomor 5618

Peraturan Lembaga Penjamin Simpanan Nomor 1/PLPS/2007 tentang Program Penjamin Simpanan, Berita Negara Republik Indonesia Tahun 2007 Nomor 68 